\title{
GLOBAL ECONOMIC CRISIS: IMPACT ON HIGHER EDUCATION IN MALAYSIA
}

\author{
RAMLI HASSAN \\ MOHAMMAD HAJI ALIAS
}

\begin{abstract}
The global economy is reeling from the effects of financial crisis which led to an economic crisis triggered by the United States sub-prime mortgage crisis which started in late 2007. The sharp inflation in petroleum and food prices in the first half of 2008 also compounded the problem. The National Bureau of Economic Research (NBER) had declared that the US economy had been in recession since December 2007. Contraction in the growth rates of major developed economies thereby causing global trade in goods and services to plummet has affected open economies including Malaysia. Last year Malaysian GDP grew by about $4.6 \%$ over 2007. An ominous sign that economic growth in 2009 would be low or even negative was the $0.1 \%$ growth in GDP in the fourth quarter of 2008 compared to the same quarter in 2007. This was due mainly to a $40 \%$ drop in net exports. The slow down in growth has affected all sectors of the economy. Education in general and higher education in particular are not spared. Higher education has to compete for scarce public funds. The main objective of this paper is to understand the impact of the global economic crisis on higher education in Malaysia. A better understanding is imperative in order to prepare for the challenges ahead. The challenges ahead are within the framework of the new economic model being formulated by the government in order to lift Malaysia into a high income country within a decade. A major critical success factor is the implementation of an effective human capital development strategy.
\end{abstract}

Keywords: Economic crisis; higher education; recession.

\section{Introduction}

Countries in Asia are increasingly worried about what is happening in the West, especially with regard to the weaknesses in the US financial industry precipitated by the sub-prime mortgage crisis. The financial crisis in the US which started in 2007, was transmitted to the real sector as the credit crunch and debt deflation led to job losses 
and contraction in consumer spending (Goh, Alias \& Tan, 2009). The ensuing downturn in the US economy affected other regions and countries especially export-driven economies. Asian countries such as Malaysia have not had a sub-prime mortgage crisis of the magnitude experienced by the United States. On the contrary, many Asian nations have witnessed rapid growth and wealth creation in recent years. However, this crisis has shown that in an increasingly inter-connected world there are always systemic effects rippling throughout the global front and as a result, Asia including Malaysia has had more exposure to problems stemming from the West, particularly so because of its open economy.

The Malaysian Institute of Economic Research (MIER) has revised downwards its forecast of the country's gross domestic product (GDP) for 2009 to $-2.2 \%$ from $1.3 \%$ earlier on the back of export slump arising from the global economic turmoil. The private think-tank said it was almost certain that Malaysia's growth would slide into a technical recession in the first half of 2009.

It said exports were expected to be reduced by $24.0 \%$. The crisis may not hit the bottom and if exports continue to shrink adversely, the downturn could be more harmful. MIER said the Malaysian economy would recover gradually to $3.3 \%$ in 2010 (MIER, 2008). It had earlier forecast growth of 3.8\% for 2010. Bank Negara Malaysia (BNM) had projected the country's economy to contract by $-1.0 \%$ or to growth of 1\% in 2009. The Bank Negara Annual Report 2009 has given a preliminary growth rate of $-1.7 \%$ for 2009 (Bank Negara Malaysia, 2010). The government has introduced two economic stimulus packages worth a combined RM67.0 billion to boost the economy affected by global economic recession. The benefits from the two stimulus plans could only be seen by year's end.

The focus of this article is on the impact of the global financial crisis on higher education. This article is structured as follows. The section after the introduction gives a general discussion on the impact of the global economic recession on higher education. This is followed by a discussion on the impact of the global financial crisis on higher education and policy responses in Malaysia. The final section gives the summary and conclusion.

\section{Impact of the Global Economic Crisis on Higher Education}

It is imperative that higher education institutions, particularly universities, must strategise to strengthen their roles in ensuring 
the nation's economic and social progress in this highly uncertain, fiscally-brutal environment.

Essentially the impact on higher education due to the global economic crisis is as follows;

- $\quad$ universities are proving to be appealing investments for government stimulus efforts due to the sector's stabilising, countercyclical nature in the short term as well as its potential to stimulate long term economic growth, and

- most universities demonstrate countercyclical ability to increase student enrollments during recessions, receive relatively strong support from sponsoring governments, and offer long term potential for increasing revenue diversity.

A useful graphic on the enrollment impact of recessions is depicted in the following.

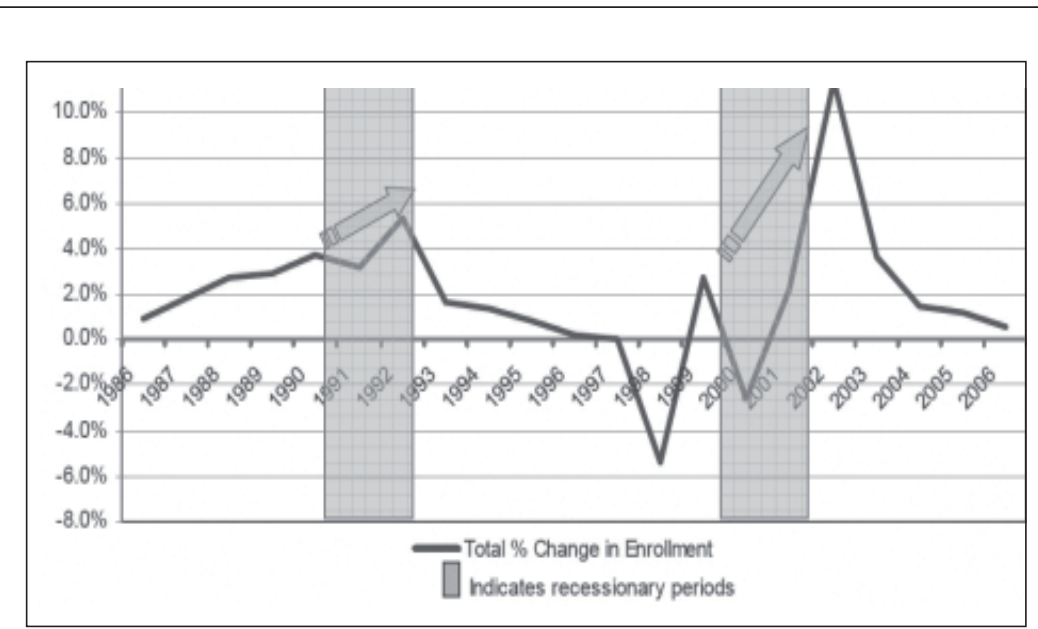

Foonotes: OECD Education at a Glance Data, avaiable at http://stats.oecd.org; Percentage Change in Total Enrollment for Canada, France, Italy, Spain, United Kingdom, and United States. Group chosen as only countries with complete data going back to 1985 in OECD countries.

Figure 1. Enrollment Impact of Recessions; Enrollment Grows More Rapidly During and Year After Recession; Largest Dips in Boom Years.

In other words, as the economy nose-dives, individuals are more likely to consider investing in more education as a means of waiting out the recession, and positioning themselves for the labour market 
when it revives. This all means a possible tail-wind for universities as student demand increases, particularly those who have an access oriented agenda.

Basically there are five key areas that are likely to be affected by the global economic crisis such as:

1. while universities will experience some economic stress, they will be more sheltered than other sectors as demand increases for higher education;

2. public university credit quality will be steadier than that of private universities as many private institutions may not be sustainable due to credit squeeze or crunch;

3. private universities can achieve a high rating if they are able to show evidence of sustained demand and financial strength, and liquidity is clear;

universities are likely to seek more alternative sources of funding to offset the pressure on government balance sheets and limitations on public funding growth; and

5. despite efforts at diversifying, the public sector will continue to play a central role in higher education growth ${ }^{1}$.

There are several issues worth noting here. The first is that individuals have been encouraged to invest in a graduate education, very often at considerable personal expense (loans and so on) with the promise of future earnings that outpace non-graduate earnings. If wages are depressed across the public and the private sectors because governments and firms have to manage the consequences of bailing out the banks, then a graduate education might be more appealing than the work environment for graduating students. This in turn would make individuals more likely to consider advancing their education level, consequently increase the demand for access to higher education.

\section{Impact on Higher Education in Malaysia}

The continual global economic crisis will certainly have impact on Malaysia's higher education in the following aspects: 
- budget constraints and limited allocation for public universities;

- investment of private higher education providers will be affected;

- $\quad$ higher demand for tertiary education especially post-graduate levels as students may defer entering the job market due to weakening job markets;

- increase in the number of unemployed graduates as the economy enters the recession phase; and

- $\quad$ types of programmes offered at higher education institutions need to meet the changing market demand.

On the onset of the global economic crisis, the government has no choice but to introduce various mechanisms for prudent spending on all institutions under its purview such as universities, polytechnics, and community colleges. Malaysia may encounter more severe financial meltdown if mitigating efforts are not taken immediately.

Initiatives have been taken in building world-class higher education and human capital development in Malaysia to restructure its economy toward knowledge-, creative- and innovative-based sectors. The launching of the National Higher Education Strategic Plan (NHESP) by the former Prime Minister on 27 August 2007 was a significant milestone in transforming the higher education sector. Presently, the Ministry of Higher Education (MoHE) is actively pursuing this strategic plan guided by its five pillars of excellence and 18 critical agendas to transform the landscape of higher education sector in Malaysia.

The policy of the MoHE is essentially guided by:-

i. the pursuit of excellence in teaching, training, research, and institutional performance;

ii. the relevance of services offered by higher education institutions to the perceived priority needs of their respective societies; and

iii. the quest for balance between short-term pertinence and service and long-range quality, between basic and applied research, and between professional training and general education.

Therefore, the initiatives to be adopted by the MoHE of Malaysia are as follows:

i. to promote linkages between world-class universities through twinning and other linking arrangements between Malaysia and higher education institutions in the industrialised and developed countries in critical areas; 
ii. to establish centres of excellence for specialised field of studies and collaboration efforts with international partners;

iii. to establish programme chairs for intensified areas of research and teaching;

iv. to respond to the need of making fuller use of cooperative efforts and sharing inter-university sharing, and to further expand the international dimension of higher education;

v. to enhance the academic mobility and the recognition of studies of diplomas and degrees through Malaysian Qualification Framework and expanding that to the full recognition by International bodies and universities; and

vi. to actively promote life-long learning, re-skilling, and upgrading of the workforce.

- $\quad$ Promote the development and use of portable credentials.

- Design programmes to meet the diverse needs of workers within the context of the workforce's changing demographics.

- Develop a system of creative incentives for human capital investments by individuals and businesses to fill critical skill gaps identified through community audits, and to meet future needs identified in community economic development plans.

The emphasis placed on human capital in the NHESP reflects the seriousness and determination in creating a pool of highly competent knowledge workers. Malaysia's ability to carve out significant competitive advantage in certain industries lies in the people factor, requiring them to attain a high level of competence and skills. Essentially, it is through higher education and training that Malaysia can be prepared to face the challenges that global economic recession has brought about in the last couple of years.

- In reality, the formulation of NHESP is an important step forward for the MoHE to strategise the national economic growth and development via the output of skilled and competent human capital at the institutions of higher education, despite the global economic recession. The NHESP has outlined seven strategic thrusts in strengthening the higher education sector to be resilient and remain competitive both in challenging and difficult times due to the economic downturn. The higher education sector remains the core pillar in producing human capital with first class mentality contributing toward the growth of the national economy.

The renewal and transformation of higher education toward wider access and better quality to higher education are crucial factors for 
the national development. These efforts are aimed at improving the relevancy of curriculum and the efficiency and effectiveness of the delivery system in producing the required knowledgeable and versatile human capital which in turn can contribute positively to the community at large. However, the challenges during this global economic crisis will be the availability of sufficient funding to support both operational as well as developmental expenditures in HEIs. Hence, the need for prudent and high value for money funding and investment in higher education is paramount to the success factor in driving excellence and achieving the objectives of the NHESP.

Basically, access and equity in higher education will be affected due to budgetary cuts. Likewise, other critical agendas on internationalisation, quality, governance, and others will also become critically affected and MoHE will need to realign its priorities and minimise the effect of the economic downturn. It is of utmost importance that HEIs embark on an austerity drive without compromising on its quality and standards of education provided. Similarly, the financial management of HEIs must be strengthened through greater transparency, integrity, and accountability.

In summary, the impact on the seven strategic thrusts of the NHESP due to the global economic recession is shown in Figure 2, 3 and 4 below. 


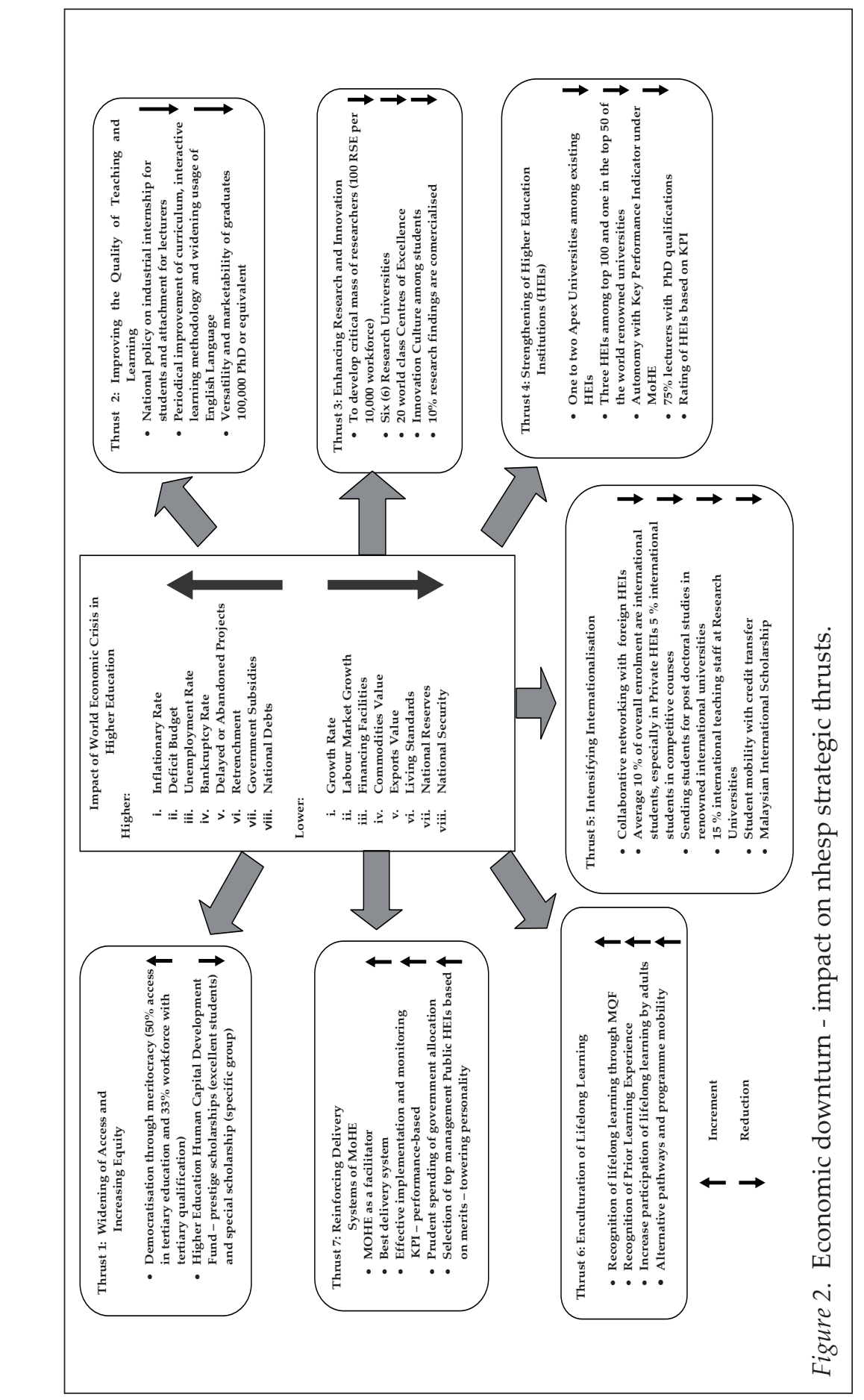

150 IJMS 17 (Special Issue), 143-154 (2010) 


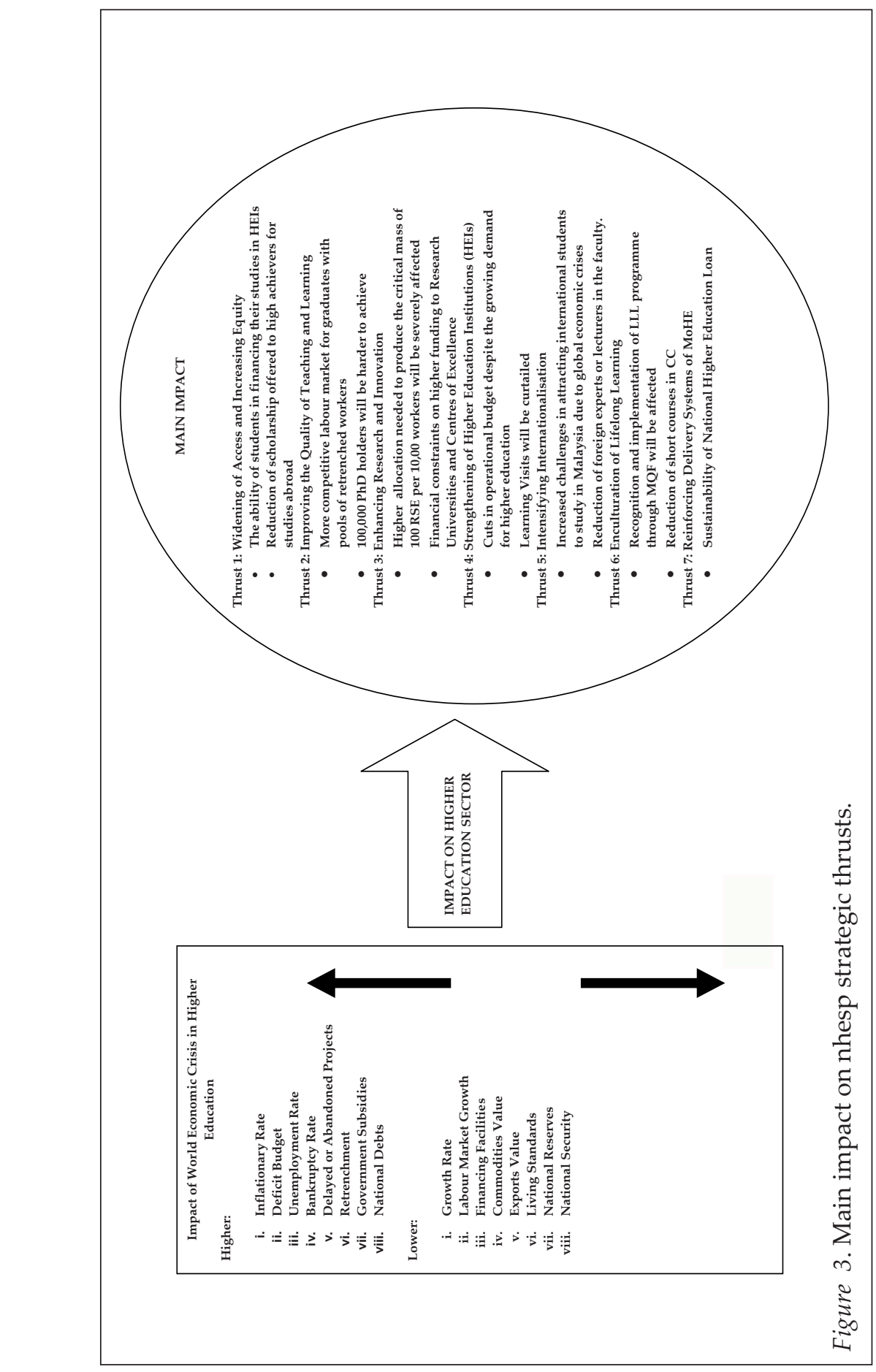

IJMS 17 (Special Issue), 143-154 (2010) 151 

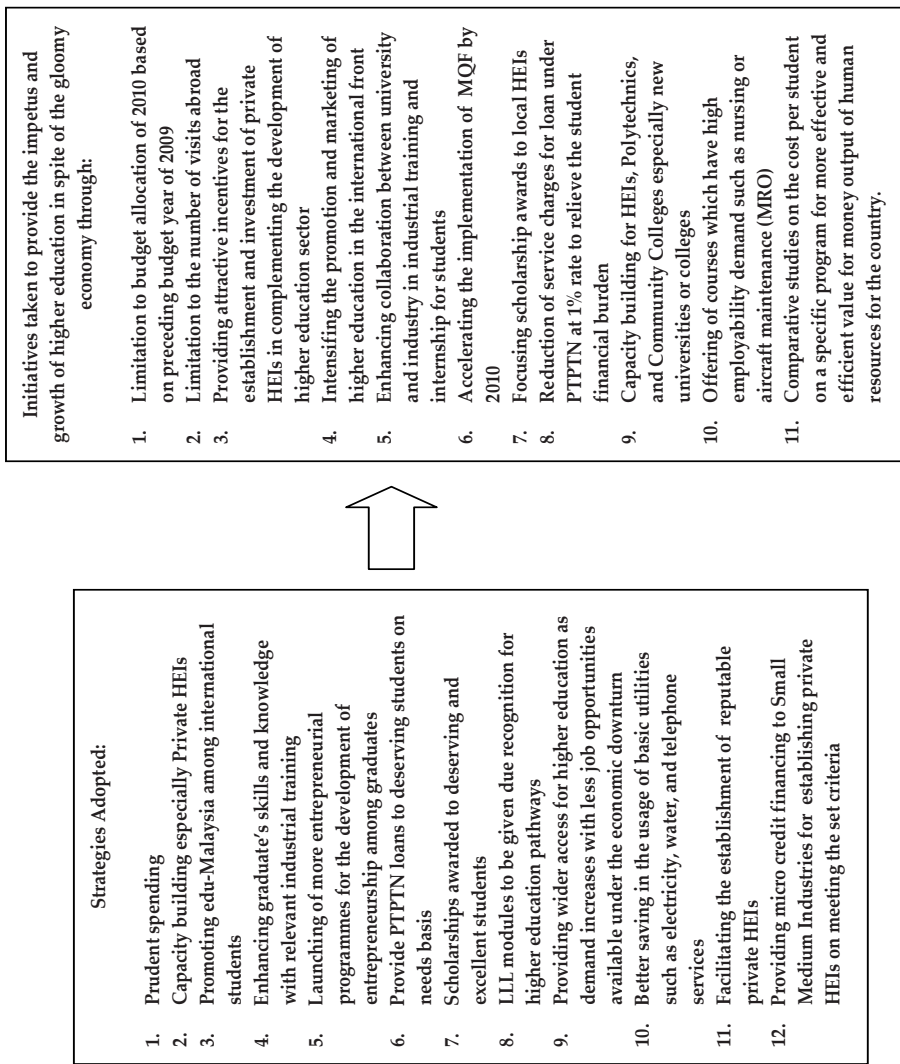

$\frac{\infty}{9}$

.

등

ช

중

$\stackrel{\vartheta}{ \pm}$

눙

م

छ

운

봉

표

D

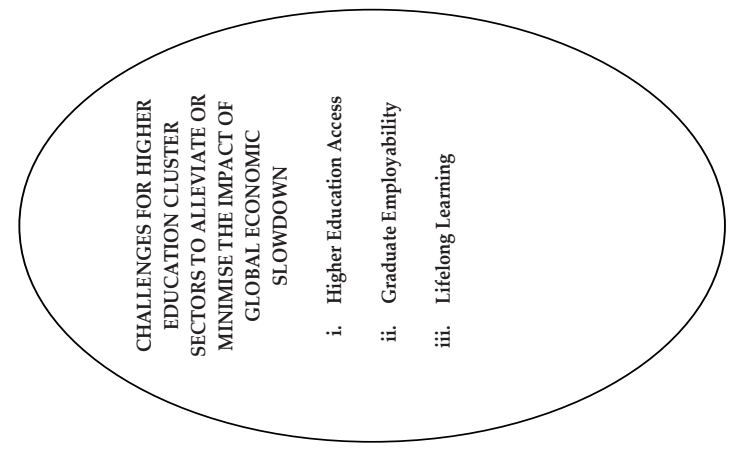

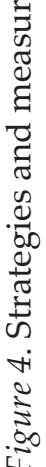

152 IJMS 17 (Special Issue), 143-154 (2010) 


\section{Summary and Conclusion}

The main objective of this article has been to understand the effect of the global economic crisis on the higher education sector in Malaysia. The global economic crisis has impacted on the real sector of the Malaysian economy via the trade channels. The consequent impact on government revenues translate into budget constraints and limited allocation for public universities, but there are opportunities to be exploited from this adverse situation.

In the current economic downturn worldwide, Malaysia needs to increase its effort to strengthen further and reinforce its higher education sector. Tremendous amount of planning is needed to channel its scarce resources for better efficiency and productivity despite the shrinking budget allocation. The government, as well as HEIs must be more accountable for their spending based on prudency, accountability, and transparency. In the economically challenging times, greater efforts and coordination are needed to ensure that issues on the employability of graduates are handled effectively. Their contribution toward nation building is ever more crucial to promote growth and prosperity as the country slides into a technical recession. MoHE will need to redouble its efforts in ensuring continuity on providing quality education and training to the citizens, and to develop its intellectual infrastructure needed for the nation's growth and sustainability. The strategies listed out will need the support and adoption from all the stakeholders including other ministries and agencies to ensure its success. MoHE is confident that the national economy is poised to reach greater heights and achievements through continuous improvement and its ability to harness its resources in a manner that is sustainable and effectively implemented.

\section{End Notes}

1. A fine example on this is provided for by the Government of Malaysia under the Second Stimulus Package, whereby RM50.0 million is provided for those eligible to pursue Masters as well as PhDs.

\section{References}

Anup Shah. (2009). Global financial crisis: Social, political, economic and environmental isues that affect us all. Retrieved from http://www. global issues.org 